\title{
Editorial
}

\section{Revista de Psiquiatria do RS: gestão 2004-2005}

Iniciar uma gestão é sempre algo desafiador e estimulante. Iniciar esta tarefa após uma gestão anterior de pleno sucesso apresenta, além do desafio habitual, uma enorme responsabilidade. Pensamos que é desta forma que iniciamos todos - Editores, Conselhos Editorial e Consultivo - esta nova tarefa à frente da Revista de Psiquiatria do Rio Grande do Sul para o biênio 2004-2005: plenos de desafios, de estímulos e da responsabilidade em manter o altíssimo nível da última gestão. Nível este, aliás, que foi a soma de todas as gestões dos vários colegas que ocuparam papéis primordiais no bom andamento de nossa Revista nestes seus 25 anos de atividades ininterruptas. Esta é, talvez, uma de nossas maiores responsabilidades. Somos a gestão que tem a ventura de ser responsável, momentaneamente, pelos destinos de nossa Revista justamente quando de seu aniversário de um quarto de século.

Sabíamos que, ao assumirmos a Revista de Psiquiatria do RS, dois objetivos estariam postos: manter a experiência bem sucedida e a continuidade do trabalho anterior e tentar acrescentar ainda mais capacitação e inovações. Isso se deu inicialmente quando da escolha, pelo Presidente da SPRS Alfredo Cataldo Neto, dos editores. Um da gestão anterior e outro novo. Da mesma forma, compusemos o Conse-
Iho Editorial com uma mescla de colegas que já faziam parte do Conselho anterior com novos nomes que vieram agregar seu conhecimento e experiência. Nosso Conselho Editorial possui ainda, entendemos, uma outra mescla, qual seja, a de diferentes referenciais teóricos e subáreas da Psiquiatria. Isto confere ao conselho um caráter bastante abrangente, elemento fundamental na avaliação de artigos para uma Revista que se pretende manter plural.

Graças ao empenho fundamental da última gestão em distribuir nossa Revista para todo o país (com crescente apoio publicitário), hoje podemos dizer que a Revista de Psiquiatria do Rio Grande do Sul não é apenas uma Revista do extremo sul de nosso país, é uma Revista nacional. Isto tem ficado cada vez mais estabelecido, quer pelos artigos de vários estados do Brasil que vimos recebendo, quer por inúmeras cartas de colegas de outras partes de nosso país que têm elogiado o elevado nível científico da Revista. Em um país rico em idéias como o nosso, porém pobre em veículos de circulação nacional de excelência, entendemos que todo o espaço para publicação do conhecimento científico brasileiro é bem-vindo. Há espaço para todos.

Entre nossas metas para este período podemos citar: a manutenção rigorosa do nível 
científico e da periodicidade; a busca de novos indexadores; a elevação do fator de impacto; a continuidade da distribuição em nível nacional; o aprimoramento da publicação eletrônica através do Scielo (www.scielo.br/rprs) com edição da revista no idioma inglês para facilitar o acesso da comunidade internacional e a organização de um evento comemorativo aos 25 anos de existência da revista.

Neste número temos a satisfação de publicar nove artigos muito interessantes e uma resenha de um livro de Antônio Damásio. Dos quatro artigos originais, o primeiro artigo é da autoria de Schreiner e colaboradores, do Departamento de Psiquiatria e Medicina legal da Faculdade de Medicina da PUC-RS. Este artigo traz dados locais e trata de um tema bastante importante e comum (sintomas depressivos) em uma amostra incomum de ser estudada (prostitutas). É um artigo que certamente suscitará, em nosso leitores, inúmeras reflexões e trará à luz de nossa Ciência dados muito interessantes sobre uma população marginalizada e, por isso, pouco estudada. O segundo artigo original é de Clarissa Gama e cols, do Programa de Esquizofrenia do Hospital de Clínicas de Porto Alegre. Trata do uso da clozapina em uma amostra de 56 pacientes durante um período de tratamento de 93 meses a partir do fornecimento gratuito desta medicação pelo governo estadual do RS. Chama a atenção, neste estudo, a boa resposta desta amostra, medida pela escala BPRS, à droga e a importância do início precoce de tratamento, assim como a participação do Estado no suporte financeiro para estes pacientes. $O$ terceiro artigo original, de Flávio Shansis e cols, da Universidade Federal do Rio Grande do Sul (UFRGS), traz aos nossos leitores, mais uma vez, a versão em português de outra escala de avaliação de mania (de Bech-Rafaelsen). Com isso, nossa Revista firma-se como um veículo para a disponibilidade de escalas, tão necessárias às pesquisas realizadas em nosso país. $O$ quarto e último artigo original, de Scappaticci, lacoponi e Sérgio Blay, da Universidade Federal de São Paulo (UNIFESP EPM), trata-se de um estudo de fidedignidade inter-avaliadores de uma escala para avaliação mãe-bebê a partir da observação de 14 puérperas e seus recém nascidos. Além de ser mais um artigo em nossa revista a abordar a validação de escalas em nosso país, esta é uma pesquisa realizada acerca de uma área ainda negligenciada pela Psiquiatria. Neste número apresentamos também com satisfação cinco artigos de revisão bastante úteis. O primeiro, de Fandiño e cols, do Grupo de Obesidade e Transtornos Alimen- tares do Instituto de Psiquiatria da Universidade Federal do Rio de Janeiro (IPUB/UFRJ), aborda a atualização tanto de aspectos clínicocirúrgicos, quanto psiquiátricos, da cirurgia bariátrica no manejo de pacientes com obesidade grau III. O segundo artigo de revisão, de Silberman e cols, do Centro de Doença de Alzheimer e de outros Transtornos Mentais na velhice do Instituto de Psiquiatria da Universidade Federal do Rio de Janeiro (IPUB/UFRJ), trata do importante impacto da depressão sobre a cognição na Doença de Parkinson (DP), e conclui que a depressão é um fator de risco para a DP, assim como a DP é um fator de risco para a depressão. O terceiro artigo, de Ronchetti, Böhme e Ferrão, da Fundação Faculdade Federal de Ciências Médicas de Porto Alegre e Hospital Psiquiátrico São Pedro, traz à discussão um subtipo - PANDAS - de Transtorno Obsessivocompulsivo com sintomas atípicos que se desenvolve em crianças com história recente de infecção por Estreptococco Beta-hemolítico do Grupo A. Com este artigo, os autores abordam um modelo imunológico do TOC e chamam a atenção para intervenções profiláticas ambientais na etiologia deste subtipo de TOC. O quarto artigo, de Araújo e cols, da PUC-RS e UFRGS, realiza uma revisão a respeito do sono e dos sonhos de alcoolistas sob uma perspectiva pouco usual: a da Terapia Cognitivo-comportamental. Sugerem, os autores, que o relato dos sonhos pode ser um instrumento valioso sobre pistas a respeito do craving. Nosso quinto e último artigo de revisão, de Sílvio Vasconcellos e Gabriel Gauer, da PUC-RS, aborda o Transtorno de personalidade anti-social a partir de uma visão evolucionista, chamando a atenção para um provável caráter adaptativo deste transtorno em um ambiente primitivo de interação social. Por fim, apresentamos um ótima resenha do colega Maurício Marx e Silva sobre o livro "Looking for Spinoza: joy, sorrow and the feeling brain" do famoso neurologista e neurocientista luso-americano Antônio Damásio. Nosso resenhista chama a atenção para a proposição do autor de que mecanismos homeostáticos estariam na base dos sistemas de ética, nas religiões e no Direito, retomando o conceito de 'consiliência' de Edward Wilson (compatibilização entre as disciplinas mais subjetivas e as mais objetivas).

Pelo que se observa, portanto, pelos artigos aqui publicados de várias procedências de nosso país, que a Revista de Psiquiatria do Rio Grande do Sul - apesar do seu nome - é uma revista nacional, o que muito nos orgulha.

Agradecemos ao César Luís de Souza Bri- 
to, editor em parceria com Jacó Zaslavsky na gestão 2002-2003, por sua dedicação e incansável colaboração na continuidade do crescimento da revista.

Por último, mais uma vez ressaltamos que nós - Editores e Conselhos da gestão 20042005 - estamos empenhados em fazer o máximo para corresponder às expectativas geradas a cada nova gestão, isto é, prosseguir no cami- nho da seriedade e da ética, estimulando uma Psiquiatria brasileira da mais alta qualidade científica. Estas são funções que a Revista de Psiquiatria do Rio Grande do Sul sempre procurou manter nestes seus 25 anos de atividades.

A todos, uma boa leitura,

Flávio Shansis e Jacó Zaslavsky Editores da Revista 